\title{
Evolution of embryonic developmental period in the marine bird families Alcidae and Spheniscidae: roles for nutrition and predation?
}

\author{
J Mark Hipfner*1, Kristen B Gorman'1, Rutger A Vos² and Jeffrey B Joy ${ }^{3}$
}

\begin{abstract}
Background: Nutrition and predation have been considered two primary agents of selection important in the evolution of avian life history traits. The relative importance of these natural selective forces in the evolution of avian embryonic developmental period (EDP) remain poorly resolved, perhaps in part because research has tended to focus on a single, high taxonomic-level group of birds: Order Passeriformes. The marine bird families Alcidae (auks) and Spheniscidae (penguins) exhibit marked variation in EDP, as well as behavioural and ecological traits ultimately linked to EDP. Therefore, auks and penguins provide a unique opportunity to assess the natural selective basis of variation in a key life-history trait at a low taxonomic-level. We used phylogenetic comparative methods to investigate the relative importance of behavioural and ecological factors related to nutrition and predation in the evolution of avian EDP.

Results: Three behavioural and ecological variables related to nutrition and predation risk (i.e., clutch size, activity pattern, and nesting habits) were significant predictors of residual variation in auk and penguin EDP based on models predicting EDP from egg mass. Species with larger clutch sizes, diurnal activity patterns, and open nests had significantly shorter EDPs. Further, EDP was found to be longer among birds which forage in distant offshore waters, relative to those that foraged in near shore waters, in line with our predictions, but not significantly so.

Conclusion: Current debate has emphasized predation as the primary agent of selection driving avian life history diversification. Our results suggest that both nutrition and predation have been important selective forces in the evolution of auk and penguin EDP, and highlight the importance of considering these questions at lower taxonomic scales. We suggest that further comparative studies on lower taxonomic-level groups will continue to constructively inform the debate on evolutionary determinants of avian EDP, as well as other life history parameters.
\end{abstract}

\section{Background}

Embryonic developmental period (EDP) is an evolutionarily conservative life-history trait in birds, with $80 \%$ of the Class-wide variation residing at the taxonomic levels of order and family-within-order [1,2]. Such strong conservatism is to be expected, given that embryonic development is a tightly constrained process [3], and that egg size, which has a positive relationship with EDP, is equally conservative [1,2]. Nonetheless, EDP varies more than threefold even among avian species with eggs of similar size [4], indicating that this trait can and does respond

* Correspondence: mark.hipfner@ec.gc.ca

${ }^{1}$ Centre for Wildlife Ecology, Department of Biological Sciences, Simon Fraser University, 8888 University Drive, Burnaby, British Columbia, V5A 1S6, Canada Full list of author information is available at the end of the article strongly to natural selection. However, accounting for this variation remains an ongoing challenge [5-8].

All else being equal, we expect natural selection to favor a reduction in the time taken to complete development [9]. However, there may be fitness costs for the individual associated with its faster development, such as decreases in resistance to pathogens and parasites $[8,10,11]$ or breeding lifespan $[12,13]$, which could counteract that tendency. How then are the evolutionary trade-offs resolved, and what ultimate factors play important roles? Nutrition and predation have been considered two primary agents of selection on avian life-history traits, including the rate of development $[5,14]$. However, their roles remain somewhat poorly resolved, perhaps in part because research has tended to focus on a single, high taxonomic-level group of birds: Order Passeriformes 
[7,15-20]. Further, several basic assumptions that underlie much of the passerine research, which in general supports a primary role for predation [14], have been questioned [15]. Here, we pose a simple question: could the focused study of lower taxonomic-level avian groups help clarify the relative roles of nutrition and predation in the evolution of EDP?

Lack [5] first noted that EDP and post-EDP are positively correlated across avian species. The underlying cause of the relationship remains obscure (e.g., pleiotropy or independent unidirectional selection), and one can find exceptions to the general rule [18,21]. Nonetheless, the relationship has been demonstrated in phylogenetically-controlled analyses [2], supporting its biological relevance. Lack proposed that the correlation indicated the existence of an evolutionary predisposition for a constant growth trajectory, an idea also supported by Bennett and Owens [2]. That a relatively constant rate of development [22] is ultimately beneficial, either fast or slow depending on critical facets of a species' ecology, is consistent with recent studies documenting deleterious, long-term phenotypic consequences associated with irregular growth [12]. Consequently, we can expect rapid embryonic development to evolve more readily in species where parents can provide sufficient nutrition to support rapid post-embryonic development. If so, then behavioural and ecological factors that increase the rate at which parents deliver food should lead to coevolution of a briefer EDP.

Clutch size is another factor that could affect EDP [23]. The intensity of sibling competition for food increases with brood size, and individuals that hatch early usually outcompete late-hatched siblings, especially if hatching is asynchronous. Therefore, we can expect from existing theory that a larger clutch size selects for a briefer EDP and brood reduction as nest-mates engage in an evolutionary race to hatch first $[6,18]$.

Like nutrition, predation also has a potentially complex relationship with EDP. On the one hand, life-history theory suggests that long-lived species should accept an increased risk to their offspring when countered by a decrease in the risk to themselves. Thus, parents in longlived species should be less attentive to the nest site if that attentiveness subjects them to the risk of being depredated. This could drive the species to slower overall development as a result of frequent egg neglect [7] (but see Tieleman et al. [19]). On the other hand, it is more commonly argued that an increase in the offspring's mortality rate while in the nest could select for more rapid development in order to minimize the period of vulnerability $[5,17,24]$.

Among avian families, the Alcidae exhibit unusual variation in several behavioural and ecological traits ultimately linked to EDP in other avian groups [25]. Throughout all species within the family, both males and females incubate on approximately equal schedules and there is no feeding of incubating adults by non-incubating partners. Egg mass varies by a factor of four, while clutch size is either one or two, representing considerable variation in relative if not absolute terms. The family further exhibits unparalleled variation in the amount of time spent (species means of two-54 days), and post-EDP completed (zero to $80 \%$ ), at the nest site before offspring depart to sea, either alone, or accompanied by one or both parents $[1,26]$. Variation in the frequency of offspring provisioning is also extreme: the auks include diurnal, nearshore-feeding species that bi-parentally deliver ten to 15 meals per day; but also nocturnal, offshore species that bi-parentally deliver at most two meals per day [27]. Several species even forego provisioning at the nest site altogether as their chicks are precocial [28] and fed at sea. Moreover, a range of nest types is used. Most auks breed on mammal-free islands in enclosed earthen burrows, or rock crevices, where their eggs are inaccessible to avian predators. However, some species breed in the open, either cryptically on old-growth tree branches or in alpine tundra, while others nest very densely and conspicuously on exposed cliff ledges. For open-nesting auks, the nest site is vulnerable to avian predators, and in some situations rates of predation on eggs and chicks can be so high as to compromise population viability $[29,30]$.

The penguins, originally conflated with some auks for their morphological similarities (the now extinct great auk (Pinguinus impennis) was the original bird called penguin, from the Welsh pen gwyin, for white head [31]), and have comparable variation in the traits under study here. Like auks, in all penguin species, except the emperor penguin (Aptenodytes forsteri), both sexes take incubation shifts [32]. The lower extreme in egg mass is found in the little blue penguin (Eudyptula minor) (53 g), while the upper extreme is found in the emperor penguin $(465 \mathrm{~g})$ with most other species ranging between 100 and $150 \mathrm{~g}$ [32]. Clutch size is also one or two eggs [32]. Incubation period ranges between one and two months, while nestling period has some high extremes in the emperor and king (Aptenodytes patagonicus) penguin (150 days), with the rest of the species ranging between 49 and 90 days [32]. Like the auks, penguin nests vary from those built in crevices or burrows, to nests in the open built out of sticks and grass, to bare patches on the ground. Penguins also are vulnerable to avian predators, with low breeding success in small colonies being partially attributable to depredation [33].

Given the extent of variation in that suite of ecological and life-history traits (Table 1), it is not surprising that EDP varies widely among auk and penguin species (27 to 64 days, or approximately zero- $60 \%$ longer than predicted from egg mass; Figure 1). Therefore, these taxa provide a unique opportunity to assess variation in a key life-his- 
Table 1: Taxon identifiers, behavioural, ecological, and life-history variables used in the analysis, in addition to GenBank accession numbers

\begin{tabular}{|c|c|c|c|c|c|c|c|c|c|}
\hline Scientific name & Common name & NCBI acc ${ }^{1}$ & EDP2 & $\mathrm{EDPr}^{3}$ & EM $^{4}$ & $\mathrm{CS}^{5}$ & $\mathrm{FH}^{6}$ & $\mathbf{A P}^{7}$ & $\mathrm{NH}^{8}$ \\
\hline Alca torda & Razorbill & AJ242683 & 35 & 5.44 & 95.70 & 1 & 0 & 1 & 0 \\
\hline Alle alle & Dovekie & AJ242684 & 29 & 3.12 & 31.30 & 1 & 1 & 1 & 0 \\
\hline Uria aalge & Common murre & AJ242686 & 33 & 2.92 & 110.80 & 1 & 0 & 1 & 1 \\
\hline U. lomvia & Thick-billed murre & AJ242687 & 33 & 3.01 & 107.80 & 1 & 1 & 1 & 1 \\
\hline Synthliboramphus wumizusume & Japanese murrelet & U37306 & 31 & 4.63 & 36.60 & 2 & 1 & 0 & 0 \\
\hline S. antiquus & Ancient murrelet & U37303 & 34 & 6.99 & 44.80 & 2 & 1 & 0 & 0 \\
\hline S. hypoleucus & Xantus' murrelet & U37305 & 34 & 7.58 & 37.20 & 2 & 1 & 0 & 0 \\
\hline Cepphus carbo & Spectacled guillemot & U37292 & 27 & -1.24 & 65.10 & 2 & 0 & 1 & 0 \\
\hline C. Columba & Pigeon guillemot & U37293 & 28 & 0.20 & 57.00 & 2 & 0 & 1 & 0 \\
\hline C. grille & Black guillemot & AJ242688 & 29 & 1.77 & 47.90 & 2 & 0 & 1 & 0 \\
\hline Brachyramphus marmoratus & Marbled murrelet & U63055 & 29 & 2.47 & 38.50 & 1 & 0 & 0 & 1 \\
\hline Ptychoramphus aleuticus & Cassin's auklet & U37302 & 39 & 13.33 & 29.20 & 1 & 1 & 0 & 0 \\
\hline Aethia pusilla & Least auklet & U37104 & 30 & 5.66 & 18.70 & 1 & 1 & 1 & 0 \\
\hline A. cristatella & Crested auklet & U37087 & 34 & 7.66 & 36.30 & 1 & 1 & 1 & 0 \\
\hline Cyclorrhynchus psittacula & Parakeet auklet & U37296 & 35 & 8.55 & 37.60 & 1 & 1 & 1 & 0 \\
\hline Cerorhinca monocerata & Rhinoceros auklet & U37295 & 45 & 16.10 & 79.20 & 1 & 1 & 0 & 0 \\
\hline Fratercula corniculata & Horned puffin & U37299 & 40 & 11.24 & 75.90 & 1 & 1 & 1 & 0 \\
\hline F. arctica & Atlantic puffin & U37297 & 41 & 12.52 & 70.00 & 1 & 1 & 1 & 0 \\
\hline F. cirrhata & Tufted puffin & U37298 & 44 & 14.65 & 90.00 & 1 & 1 & 1 & 0 \\
\hline Aptenodytes forsteri & Emperor penguin & DQ137225 & 64 & 28.32 & 465.00 & 1 & 1 & 1 & 1 \\
\hline A. patagonicus & King penguin & AY139623 & 54 & 20.00 & 310.00 & 1 & 1 & 1 & 1 \\
\hline Eudyptula minor & Little blue penguin & NC_004538 & 34.7 & 7.14 & 53.00 & 2 & 0 & 1 & 0 \\
\hline Eudyptes chrysocome & Rockhopper penguin & AF076051 & 34 & 3.68 & 118.40 & 2 & 1 & 1 & 1 \\
\hline E. chrysolophus & Macaroni penguin & AF076052 & 35.45 & 4.28 & 149.46 & 2 & 1 & 1 & 1 \\
\hline E. pachyrhynchus & Fiordland penguin & DQ137210 & 33.5 & 3.18 & 118.40 & 2 & 0 & 1 & 1 \\
\hline E. sclateri & Erect-crested penguin & DQ137209 & 35 & 3.80 & 150.70 & 2 & - & 1 & 1 \\
\hline Pygoscelis adeliae & Adelie penguin & GQ925801 & 33 & 2.63 & 120.10 & 2 & 0 & 1 & 1 \\
\hline P. Antarctica & Chinstrap penguin & AF076089 & 34 & 3.81 & 114.10 & 2 & 0 & 1 & 1 \\
\hline P.papua & Gentoo penguin & AF076090 & 35 & 4.42 & 127.08 & 2 & 0 & 1 & 1 \\
\hline Spheniscus demersus & Black-footed penguin & DQ137217 & 38 & 8.05 & 106.80 & 2 & 0 & 1 & 0 \\
\hline S. humboldti & Peruvian penguin & AY567916 & 40.7 & 10.18 & 125.00 & 2 & 0 & 1 & 0 \\
\hline S. magellanicus & Magellanic penguin & DQ137218 & 41.2 & 10.65 & 126.25 & 2 & 0 & 1 & 0 \\
\hline Megadyptes antipodes & Yellow-eyed penguin & DQ137224 & 43.5 & 12.64 & 137.20 & 2 & - & 1 & 1 \\
\hline
\end{tabular}

${ }^{1} \mathrm{NCBI}$ accession number; ${ }^{2} \mathrm{Embryonic}$ development period; ${ }^{3}$ Embryonic development period residuals; ${ }^{4} \mathrm{Egg}$ mass in grams; ${ }^{5} \mathrm{Clutch}$ size;

${ }^{6}$ Foraging habitat $(0=$ inshore, $1=$ offshore $) ;{ }^{7}$ Activity pattern $(0=$ nocturnal or crepuscular, $1=$ diurnal); 8 Nesting habits $(0=$ enclosed, $1=$ open $)$.

tory trait at a low taxonomic-level. Here, we examine the influence of behavioural and ecological factors related to nutrition and predation risk in the evolution of EDPs within a comparative, phylogenetic framework. We test the following specific predictions: (1) species that provision nocturnally or crepuscularly, thus only once per day, will have longer EDPs than diurnal species; (2) species that feed in offshore habitats far from the centrallylocated nest site will have longer EDPs than inshore species; (3) species that lay a single-egg clutch, thereby lacking sibling competition, will have longer EDPs than species with two-egg clutches; and (4) species that use enclosed nest sites where offspring are safer from predators will have longer EDPs than species that use open nest 


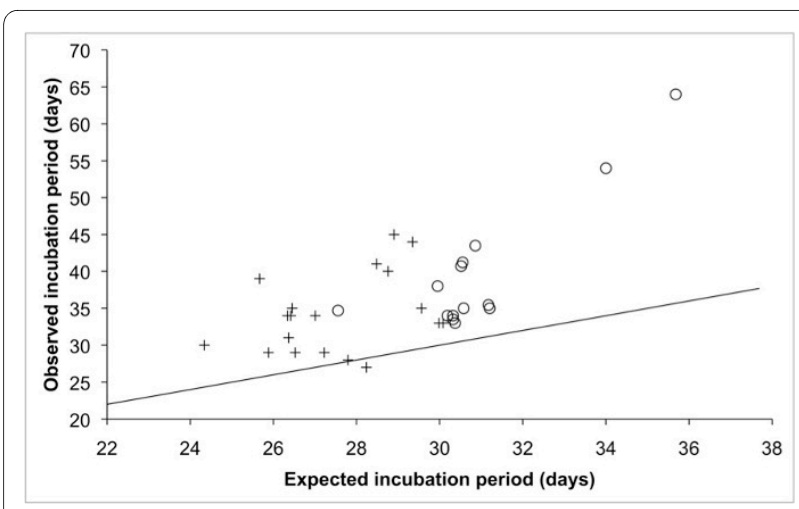

Figure 1 Embryonic developmental periods (EDP) in the auks and penguins in relation to values predicted from fresh egg mass for Charadriiform birds. The straight line represents a 1:1 relationship (i.e., observed EDP is the same as that predicted from egg mass). The equation for Charadriiform birds is: predicted EDP $=17.18 \times$ egg mass 0.119 [74]. Alcids are indicated by + , penguins are indicated by ${ }^{\circ}$.

sites. We used a maximum likelihood analysis corrected for phylogeny [34] to study the regression of EDP residuals (over those predicted by egg mass) and our four behavioural and ecological predictor variables using phylogenetic hypotheses generated from our Bayesian phylogeny estimation.

\section{Results}

\section{Phylogenetic relationships}

During our MCMC phylogenetic inference we discarded those trees sampled during the first 2.5 million (out of ten million) generations, a very safe, long burn-in given the speed of convergence. The majority rule consensus over the full set of trees sampled after burn-in generally shows that most genera are reconstructed as monophyletic groups (the only exception in the consensus being the instability of the Adélie penguin (Pygoscelis adeliae), Figure 2) and that the topology matches the current understanding of the phylogeny of the taxa under study (e.g. see for comparison Pereira and Baker [35], Bertelli and Giannini [36], and Baker et al. [37]), albeit with some nodal instability for the deeper nodes, an effect caused by saturation of sites in the cytochrome $b$ locus at this level of divergence.

\section{Comparative analysis}

The estimate for $\lambda=0.999995$ shows that the assumption of Brownian motion, which is made by many comparative analyses, holds. With an $\mathrm{r}^{2}=0.444949$, our independent variables explained a large proportion of the variation in the dependent variable. Of our independent variables, clutch size had the greatest (negative) influence on EDP, a result that was highly significant $(\mathrm{p}<0.01)$, confirming the prediction that an arms race between siblings for early hatching should drive the evolution of shorter EDP

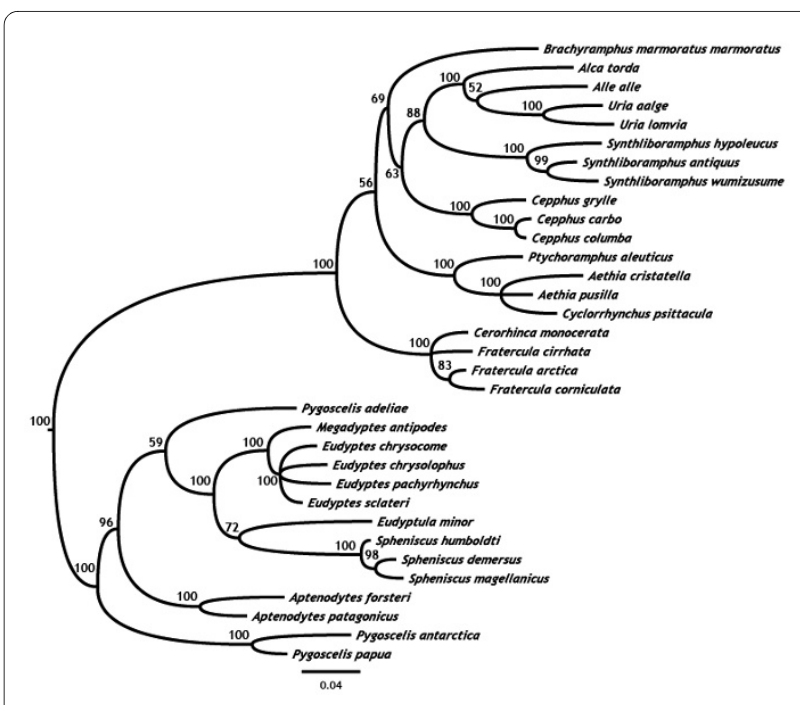

Figure 2 Auk and penguin phylogenetic relationships. Majority rule consensus tree, pruned to include species for which life history data were available, with Bayesian nodal posterior probabilities as inferred from mitochondrial cytochrome $b$ gene sequence data.

in species with two-egg clutches relative to those with one-egg clutches $[6,18]$. Activity pattern and nesting habits also both significantly affected EDP, in the direction predicted: diurnal taxa had shorter EDP, presumably due to their higher provisioning rates, and taxa with open nests had shorter EDP, presumably due to higher predation risk. Although the standardized coefficient for foraging habitat suggested an effect in the predicted direction (offshore foragers seem to have longer EDP), this effect was not significant (see Table 2 for analysis results).

\section{Discussion}

EDP in the auks and penguins tend to be longer than predicted by egg mass (Figure 1). Long developmental periods are characteristic features of the life-histories of

Table 2: Regression analysis results

\begin{tabular}{lll}
\hline Variable & Standardized coefficient & Standard error \\
& & \\
\hline Clutch size & $-8.337654^{* *}$ & 2.552405 \\
Offshore foraging & 1.990214 & 1.575975 \\
Diurnality & $-3.497337^{*}$ & 1.695883 \\
Open nests & $-4.164798^{*}$ & 2.258906 \\
\hline
\end{tabular}

Summary of the (phylogenetically corrected, reasonably assuming Brownian motion given $\lambda=0.999995)$ analysis of the regression of auk and penguin embryonic developmental period (EDP) residuals (computed from the EDP predicted from egg mass) on clutch size, foraging habitat $(0=$ inshore, $1=$ offshore $)$, activity pattern $(0=$ nocturnal or crepuscular, $1=$ diurnal) and nesting habits $(0=$ enclosed, $1=$ open). The independent variables explain a large amount of the variation in EDP $\left(r^{2}=0.444949\right)$. Alpha $=28.483666$ (s.e. $=5.898111$ ), likelihood $=-79.736323$. 
oceanic birds [5]. Here we have investigated the influence of several behavioural and ecological factors, proxies for nutrition and predation, on EDP in these taxa. Our results support the hypothesis that surrogates related to both nutrition and predation played important roles in shaping the evolution of EDP within alcids and penguins.

\section{Effect of behavioural and ecological variables on EDP}

Firstly, the most important variable affecting EDP was clutch size. As predicted, larger clutches seem to drive the evolution of shorter EDP presumably due to an arms race between siblings for early hatching $[6,18]$. Among our taxa, most of the two-egg clutches were confined to the penguins; it is noteworthy that in auks the two-egg clutch is found exclusively among two clades: the guillemots, nearshore specialists that provision very frequently [38]; and the murrelets of the genus Synthliboramphus in which parents take their two chicks to sea, thus to the food source, within a day or two after hatching [28].

Secondly, EDP tends to be longer in those taxa that attend the colony nocturnally or crepuscularly rather than diurnally. Nocturnality is thought to have evolved in seabird groups primarily to reduce predation on adults while visiting colonies [28,39]. From the perspective of the offspring, nocturnal provisioning decreases the rate of postembryonic development because it restricts the number of energetically demanding [40] provisioning trips that each parent makes to one per day [27]. Given some direct or indirect mechanistic link between EDP and post-EDP, we can expect nocturnality to be associated with slower embryonic development. In the auks, the strong effect of nocturnality on EDP is perhaps most clearly evident in the Aethiini and Fraterculini: in both tribes, the basal species, including Cassin's auklet (Ptychoramphus aleuticus) and rhinoceros auklet (Cerorhinca monocerata), is nocturnal, delivers at most one meal per parent per day to the nest site $[27,41]$, and has a very long EDP (and post-EDP).

Thirdly, we found an association between longer EDP and the use of enclosed, rather than open nest sites, an association also observed in other avian groups [42]. Like previous authors, we attribute this to the fact that offspring experience higher predation risk at open nest sites. There are few open-nesting auk species, but among these few, avian predators (i.e., larids and corvids) prey heavily on murre eggs and chicks at cliff sites [43,44], as do corvids on marbled murrelet eggs and chicks at nests on tree branches in old-growth forests [30]. Because most auks breed on islands free of terrestrial mammals [25], and because their fully enclosed nest sites are inaccessible to avian predators, egg predation is rare or non-existent under most natural conditions in burrow- and crevice- nesting auks [25]. On the other hand, relatively more penguins are open-nesting, and nest predation by skuas, gulls and petrels is a common occurrence [33].

Because of the mortality risk at open-topped nest sites, one of the two parents must always remain to guard the offspring throughout the period of post-EDP on the colony; or, analogously, adult penguins must guard the juveniles that assemble in crèches. That requirement for protection reduces the maximum provisioning rate at the nest [45]. Therefore, we might expect nesting habits to have opposing influences on EDP due to nutrition (longer) and predation risk (shorter). That murre EDP is brief relative to egg size for an auk (Figure 1) suggests that the mortality risk has been a very strong selective factor. It is interesting therefore that limits on the provisioning rate, rather than predation risk, usually are considered the primary drivers of the evolution of the unusually brief nestling periods in alcids $[26,46,47]$, but see Cody [48].

Finally, our results further suggest that foraging habitats (nearshore or offshore) also help shape the evolution of auk EDP. This factor operated in the predicted direction: EDP tended to be briefer in taxa that feed in less distant, nearshore waters, which in seabirds facilitates increased rates of provisioning and post-embryonic growth $[5,49]$. However, the influence of this variable was not statistically significant in our results.

\section{Data quality and availability}

In the present study, we have used behavioural and ecological surrogates for offspring growth and mortality (i.e., nutrition and predation), rather than direct measures such as are used widely in other studies; see for example Martin [14]. However, comprehensive vital rate estimates are available for relatively few species [25,32], and complete measures of growth rate are lacking entirely in auk clades in which offspring complete all (all four species of Synthliboramphini) or most (three of four species of Alcini) of their post-natal growth at sea. Moreover, the quality of the information is somewhat uneven (e.g., invasive techniques are required to study hole-nesting species, some of which are highly sensitive to disturbance $[28,50])$. Even within species for which a considerable amount of reliable information is available, such as the open-nesting murres (Uria spp.), which are widely studied throughout their range using standardized, non-invasive protocols [51], growth and mortality rates can vary dramatically from year to year and site to site [52]. The variation can be driven by a number of factors, including colony size and thus intraspecific competition [53] and oceanographic variability [54]. In sum, with the available data it simply is not feasible to use direct estimates, especially given that sample sizes for our analyses are already necessarily small. 


\section{Other factors}

One factor we would have liked to consider directly is adult survival rate. For example, we noted that species with high adult survival rates might be less attentive to their offspring, if attending the nest subjects them to an unacceptable mortality risk $[7,55]$. The key prediction of this hypothesis is that there is a positive correlation between the amount of egg neglect and the duration of EDP [19]. While this basic prediction is supported intraspecifically in the auks [56], the hypothesis is not tenable applied across species. Egg neglect is rare in the two auk clades with the longest EDPs for egg mass, the Aethiini and the Fraterculini [25]. Neglect is also rare (albeit slightly less so) in murrelets (Brachyramphus spp.) and guillemots (Cepphus spp.), and all but non-existent in murres (Uria. spp.), whose eggs would almost certainly be taken by predators or roll away from the nest site if left alone. In fact, egg neglect is common only in the murrelets (Synthliboramphus spp.), in which EDP is intermediate relative to egg mass. Thus, there is no simple positive association between frequency of egg neglect and EDP, and further, there also is no simple association between egg neglect and the suite of predictor variables used in our analysis.

More generally, the limited data available on adult survival rates are equivocal in relation to the idea that long lifespan is linked to slow development, thus long EDPs and their predictors. In the Aethiini, a reasonably well studied clade, adult survival averages $87 \% \pm 4(95 \% \mathrm{CI})$ in the diurnal least auklet (Aethia pusilla) [57] and $86 \% \pm 2$ in diurnal crested auklet (Aethia cristatella) [58]; but in nocturnal Cassin's auklet, with the longest EDP in the tribe, various studies document similar survival rates of $88 \% \pm 5$ [59]; $84 \% \pm 4$ in females and $0.75 \pm 0.03$ in males [60]; and $0.789 \pm 0.040$ (SE) and $0.774 \pm 0.036$ (SE) for males and females [61]. Likewise, within the Fraterculini, survival in the nocturnal rhinoceros auklet, with the longest EDP in the tribe, averaged $0.86 \pm 0.02$ (both sexes), lower in general than in the diurnal tufted puffin (Fratercula cirrhata), $0.96 \pm 0.05$ for females and $0.91 \pm 0.06$ for males [60]; and for diurnal, brief EDP Atlantic puffin (Fratercula arctica) survival was $89-99 \%$ in 19/20 years, but dropped to $81 \%$ in $1 / 20$ years [62]. In aggregate, however, previous studies do as predicted indicate a particularly low adult survival rate relative to body mass in the guillemots (Cepphus spp.), in which parental investment appears to be particularly high due to their two-egg clutch, very high provisioning rates, and fast development [63].

The question remains as to what proximate mechanisms facilitate the evolutionary responses to selection on EDP. In the auks, eggshell porosity and EDP are negatively related, after controlling for egg size [64]. Thus, a reduction in the EDP might be achieved in part by pro- viding the developing embryo with access to more oxygen to fuel its metabolism. Maternally derived yolk hormones also could be involved; there is some evidence that yolk testosterone levels are higher in avian species with briefer EDPs [65,66], but see Gill et al. [67]. However, to date there has been no investigation of the role of yolk hormones in the evolution of auk EDPs.

\section{Conclusion}

Much current debate centers on the relative importance of nutrition and predation in avian life-history evolution $[6,7,18]$. Bennett and Owens [2] concluded that it was the adoption of different nest types, which largely determine predation risk, which acted as the primary catalyst for life-history diversification in ancient avian lineages. Food availability, they argued, was mainly involved in population regulation, rather than life-history diversification, a view that is in contrast with Lack [5]. We found evidence that both nutrition and predation have played roles in shaping the evolution of EDP at the lower taxonomiclevel of the alcids and penguins. We suggest that a full understanding of the nature of avian life-history evolution will require additional studies that focus on lowerlevel taxonomic groups, especially those, like the taxa studied here, that exhibit marked interspecific variation in life-history traits. Further, speciose clades for which reliable data on key factors are available will generate conclusions based upon more robust sample sizes and lend stronger inference concerning the evolution of avian life-histories drawn from comparative studies. Future studies also could comprehensively investigate the roles of other ultimate factors, such as extra-pair fertilization rates [18] and parasites [8].

\section{Methods}

\section{Phylogenetic inference}

We collected nucleotide sequences for the mitochondrial cytochrome $b$ locus from GenBank [68] and aligned these using BioPerl's [69] wrapper around MUSCLE [70], obtaining a multiple sequence alignment of 1144 columns. We then used reversible jump for selection of all prior parameters and the BayesPhylogenies program [71] to construct a Markov chain of trees, using a general time reversible [72] model of sequence evolution with 4 discrete gamma rate heterogeneity categories. We ran the chain for $3 * 10^{6}$ generations, sampling topologies every $30,000^{\text {th }}$ generation and allowing a burn-in of $25 \%$ of the resulting chain, i.e. omitting the first 750,000 generations. We rooted the remaining trees on our putative outgroup, great crested grebe (Podiceps cristatus), which we then pruned from the trees. We subsequently built a Majority Rule consensus tree, which is the tree we used for the remainder of the analysis. 


\section{Comparative analysis}

We collected the following comparative data from the recent literature [25,32,73]: EDP in days, egg mass in grams, clutch size, foraging strategy $(0=$ inshore foraging, $1=$ offshore foraging $)$, activity pattern $(0=$ nocturnal or crepuscular, $1=$ diurnal $)$ and nest type $(0=$ enclosed nest, burrow, rock cracks or caves, $1=$ open nests). For some of the taxa for which we found sequence data we were unable to locate comparative data: four penguin species including snares (Eudyptes robustus), royal (Eudyptes schlegeli), white-flippered (Eudyptula albosignata), and Galapagos (Spheniscus mendiculus) penguins, in addition to four alcids Craveri's (Synthliboramphus craveri), Kittlitz's (Brachyramphus brevirostris), long-billed (Brachyramphus marmoratus perdix) murrelet, and whiskered auklet (Aethia pygmaea). Based on the relationship of expected $E D P=17.18 \times$ egg mass ${ }^{0.119}$ for the Charadriiformes [74] we calculated the residuals of EDP from this slope (See Table 1).

Using our pruned consensus tree, we then analyzed the regression of EDP residuals on the combination of clutch size, foraging strategy, activity pattern and nest type using the continuous maximum likelihood regression method of the BayesTraits program [34]. The commonly-explored $\kappa$ parameter (for stretching of long branches relative to short branches) and $\delta$ parameter (overall path length scaling) were omitted from the calculations reported here. We did estimate the $\lambda$ parameter, which quantifies the influence of shared ancestry on the patterns of covariance among the taxa for a given trait. This parameter is used to test whether one of the underlying assumptions in comparative analysis holds: that species values are not independent for a given tree and trait. Values of $\lambda$ near 1.0 are interpreted to mean that the Brownian motion model is a correct representation of the data.

The comparative analysis reports the standardized coefficients (sometimes called $\beta$ ) and the standard error for each of the independent variables. The biological interpretation of the effect of each independent variable on EDP follows from the sign of the coefficient, and the ttest statistic is calculated from its division by the standard error (degrees of freedom are the number of taxa) (C. Venditti, pers. comm.).

\section{Authors' contributions}

JMH conceptualized the study; JMH and JBJ collected life-history data; KBG and RAV collected cytochrome $b$ sequence data; RAV developed phylogenetic relationships and performed comparative analysis. All authors contributed to the writing and approved the final manuscript.

\section{Acknowledgements}

We thank A. Meade and C. Venditti for statistical advice, A.J. Gaston and T.D. Williams for discussion, and R.W. Stein, A.J. Gaston, T.D. Williams, R.C. Ydenberg and three anonymous reviewers for constructive criticism on previous drafts of the manuscript. We thank Simon Fraser University and the Centre for Wild life Ecology, a partnership between Environment Canada's Canadian Wild life Service and Simon Fraser University, for supporting our research.

\section{Author Details}

'Centre for Wildlife Ecology, Department of Biological Sciences, Simon Fraser University, 8888 University Drive, Burnaby, British Columbia, V5A 1S6, Canada, 2Reading Evolutionary Biology Group, School of Biological Sciences, University of Reading, Philip Lyle Building Level 4, Reading, RG6 6BX, UK and ${ }^{3}$ Department of Biological Sciences, Simon Fraser University, 8888 University Drive, Burnaby, British Columbia, V5A 156, Canada

Received: 7 March 2009 Accepted: 14 June 2010 Published: 14 June 2010

\section{References}

1. Ricklefs RE, Starck JM: Embryonic growth and development. In Avian Growth and Development: Evolution within the Altricial-Precocial Spectrum Edited by: Starck JM, Ricklefs RE. London, UK: Oxford University Press; 1998:31-58.

2. Bennett PM, Owens IPF: Evolutionary Ecology of Birds New York, NY: Oxford University Press; 2002.

3. Starck JM: Structural variants and invariants in avian embryonic and postnatal development. In Avian Growth and Development: Evolution within the Altricial-Precocial Spectrum Edited by: Starck JM, Ricklefs RE. London, UK: Oxford University Press; 1998:59-88.

4. Rahn $\mathrm{H}, \mathrm{Ar} \mathrm{A}$ : The avian egg: incubation time and water loss. Condor 1974, 76:147-152.

5. Lack D: Ecological Adaptations for Breeding in Birds London, UK: Methuen 1968.

6. Ricklefs RE: Sibling competition, hatching asynchrony, incubation period, and life span in altricial birds. In Current Ornithology Volume 11 Edited by: Power DM. New York, NY: Plenum Press; 1993:199-276.

7. Martin TE: A new view of avian life-history evolution tested on an incubation paradox. PRoy Soc B-Biol Sci 2002, 269:309-316.

8. Moller AP: Parasites, predators and the duration of developmental periods. Oikos 2005, 111:291-301.

9. Stearns SC: The Evolution of Life Histories New York: Oxford University Press; 1992.

10. Ricklefs RE: Embryonic-development period and the prevalence of avian blood parasites. P Natl Acad Sci USA 1992, 89:4722-4725.

11. Lee KA, Wikelski M, Robinson WD, Robinson TR, Klasing KC: Constitutive immune defences correlate with life-history variables in tropical birds. J Anim Ecol 2008, 77:356-363.

12. Metcalfe NB, Monaghan P: Compensation for a bad start: grow now, pay later? Trends Ecol Evol 2001, 16:254-260.

13. Ricklefs RE: Embryo development and ageing in birds and mammals. $P$ Roy Soc B-Biol Sci 2006, 273:2077-2082.

14. Martin TE: Avian life-history evolution in relation to nest sites, nest predation, and food. Ecol Monogr 1995, 65:101-127.

15. Geffen $E$, Yom-Tov $Y$ : Are incubation and fledging periods longer in the tropics? J Anim Ecol 2000, 69:59-73.

16. Ghalambor CK, Martin TE: Comparative manipulation of predation risk in incubating birds reveals variability in the plasticity of responses. Behav Ecol 2002, 13:101-108.

17. Remes $V$, Martin TE: Environmental influences on the evolution of growth and developmental rates in passerines. Evolution 2002, 56:2505-2518.

18. Lloyd JD, Martin TE: Sibling competition and the evolution of prenatal development rates. PRoy Soc B-Biol Sci 2003, 270:735-740.

19. Tieleman BI, Williams JB, Ricklefs RE: Nest attentiveness and egg temperature do not explain the variation in incubation periods in tropical birds. Funct Ecol 2004, 18:571-577.

20. Palacios MG, Martin TE: Incubation period and immune function: a comparative field study among coexisting birds. Oecologia 2006, 146:505-512.

21. Ricklefs RE: Prolonged incubation in pelagic seabirds - comment. Am Nat 1984, 123:710-720.

22. Ricklefs RE: Embryo growth rates in birds and mammals. Funct Ecol 2010, 24:588-596.

23. Werschkul DF, Jackson JA: Sibling competition and avian growth-rates. Ibis 1979, 121:97-102.

24. Bosque C, Bosque MT: Nest predation as a selective factor in the evolution of developmental rates in altricial birds. Am Nat 1995 $145: 234-260$

25. Gaston AJ, Jones IL: The Auks New York, NY: Oxford University Press; 1998. 
26. Sealy SG: Adaptive significance of post-hatching developmental patterns and growth rates in the Alcidae. Ornis Scand 1973, 4:113-121.

27. Adams J, Takekawa JY, Carter HR: Foraging distance and home range of Cassin's auklets nesting at two colonies in the California Channel Islands. Condor 2004, 106:618-637.

28. Gaston AJ: The Ancient Murrelet: A Natural History in the Queen Charlotte Islands London, UK: T\&AD Poyser; 1992

29. Gilchrist HG: Declining thick-billed murre Uria lomvia colonies experience higher gull predation rates: an inter-colony comparison. Biol Conserv 1999, 87:21-29.

30. Peery MZ, Beissinger SR, Newman SH, Burkett EB, Williams TD: Applying the declining population paradigm: diagnosing causes of poor reproduction in the marbled murrelet. Conserv Biol 2004, 18:1088-1098.

31. Webster's Encyclopedic Unabridged Dictionary of the English Language 1996 edition. New Yok, NY: Random House; 1996.

32. Williams TD: The penguins: Spheniscidae New York, NY: Oxford University Press; 1995

33. Emslie SD, Karnovsky N, Trivelpiece W: Avian predation at penguin colonies on King George Island, Antarctica. Wilson Bull 1995, 107:317-327.

34. Pagel M: Inferring the historical patterns of biological evolution. Nature 1999, 401:877-884.

35. Pereira SL, Baker AJ: DNA evidence for a Paleocene origin of the Alcidae (Aves: Charadriiformes) in the Pacific and multiple dispersals across northern oceans. Mol Phylogenet Evol 2008, 46:430-445.

36. Bertelli S, Giannini NP: A phylogeny of extant penguins (Aves: Sphenisciformes) combining morphology and mitochondrial sequences. Cladistics 2005, 21:209-239.

37. Baker AJ, Pereira SL, Haddrath OP, Edge KA: Multiple gene evidence for expansion of extant penguins out of Antarctica due to global cooling. PRoy Soc B-Biol Sci 2006, 273:11-17.

38. Drent $\mathrm{RH}$ : Breeding biology of the pigeon guillemot, Cepphus columba. Ardea 1965, 53:99-160.

39. McNeil R, Drapeau P, Pierotti R: Nocturnality in colonial waterbirds: occurence, special adaptations and suspected benefits. In Current Ornithology Volume 10. Edited by: Power DM. New York, NY: Plenum Press; 1993:187-246

40. Hodum PJ, Sydeman WJ, Visser GH, Weathers WW: Energy expenditure and food requirement of Cassin's auklets provisioning nestlings. Condor 1998, 100:546-550.

41. Takahashi A, Kuroki M, Niizuma Y, Watanuki Y: Parental food provisioning is unrelated to manipulated offspring food demand in a nocturnal single-provisioning alcid, the rhinoceros auklet. J Avian Biol 1999, 30:486-490.

42. Martin TE, Li PJ: Life-history traits of open-nesting vs cavity-nesting birds. Ecology 1992, 73:579-592

43. Gilchrist HG, Gaston AJ, Smith JNM: Wind and prey nest sites as foraging constraints on an avian predator, the glaucous gull. Ecology 1998, 79:2403-2414

44. Schauer JHS, Murphy EC: Predation on eggs and nestlings of common murres (Uria aalge) at Bluff, Alaska. Col Waterbirds 1996, 19:186-198.

45. Birkhead TR: Adaptive significance of nestling period of guillemots Uria aalge. Ibis 1977, 119:544-549.

46. Ydenberg RC: Growth mortality trade-offs and the evolution of juvenile life histories in the Alcidae. Ecology 1989, 70:1494-1506.

47. Houston Al, Thompson WA, Gaston AJ: The use of a time and energy budget model of a parent bird to investigate limits to fledging mass in the thick-billed murre. Funct Ecol 1996, 10:432-439.

48. Cody ML: Ecological aspects of reproduction. In Avian Biology Volume 1. Edited by: Farner DS, King JR. London, England: Academic Press; 1971:461-512

49. Dobson FS, Jouventin P: How slow breeding can be selected in seabirds: testing Lack's hypothesis. P Roy Soc B-Biol Sci 2007, 274:275-279.

50. Pierce DJ, Simons TR: The influence of human disturbance on tufted puffin breeding success. Auk 1986, 103:214-216.

51. Birkhead TR, Nettleship DN: Census methods for murres Uria spp.: a unified approach. Canadian Wildlife Service Occasional Paper 1980, 43:1-20.

52. Byrd G, Murphy EC, Kaiser GW, Kondratyev AY, Shibaev YV: Status and ecology of offshore fish-feeding alcids (murres and puffins) in the North Pacific. In The status, ecology, and conservation of marine birds of the
North Pacific Edited by: Vermeer K, Briggs KT, Morgan KH, Siegel-Causey D. Ottawa: Canadian Wildlife Service Special Publications; 1993.

53. Gaston AJ, Chapdelaine G, Noble DG: The growth of thick-billed murre chicks at colonies in Hudson Strait - inter-colony and intra-colony variation. Can J Zool 1983, 61:2465-2475.

54. Ainley DG, Boekelheide RJ: Seabirds of the Farallon Islands Stanford: Stanford University Press; 1990

55. Boersma PD: Why some birds take so long to hatch. Am Nat 1982 120:733-750.

56. Sealy SG: Interruptions extend incubation by ancient murrelets, crested auklets, and least auklets. The Murrelet 1984, 65:53-56.

57. Jones IL, Hunter FM, Robertson GJ: Annual adult survival of least auklets (Aves, Alcidae) varies with large-scale climatic conditions of the North Pacific Ocean. Oecologia 2002, 133:38-44

58. Jones IL, Hunter FM, Robertson GJ, Fraser G: Natural variation in the sexually selected feather ornaments of crested auklets (Aethia cristatella) does not predict future survival. Behav Ecol 2004, 15:332-337.

59. Gaston AJ: Annual survival of breeding Cassin auklets in the Queen Charlotte Islands, British Columbia. Condor 1992, 94:1019-1021.

60. Morrison KW: Demographic consequences of early development and extreme climate events for alcids on Triangle Island, British Columbia, M.Sc. thesis Simon Fraser University, Biological Sciences; 2009.

61. Lee DE, Nur N, Sydeman WJ: Climate and demography of the planktivorous Cassin's auklet Ptychoramphus aleuticus off northern California: implications for population change. J Anim Ecol 2007 76:337-347.

62. Harris MP, Freeman SN, Wanless S, Morgan BJT, Wernham CV: Factors influencing the survival of puffins Fratercula arctica at a North Sea colony over a 20-year period. J Avian Biol 1997, 28:287-295.

63. Hudson PJ: Population parameters for the Atlantic Alcidae. In The Atlantic Alcidae Edited by: Nettleship DN, Birkhead TR. New York: Academic Press; 1985:233-261.

64. Zimmermann K, Hipfner JM: Egg size, eggshell porosity, and incubation period in the marine bird family. Auk 2007, 124:307-315.

65. Gorman KB, Williams TD: Correlated evolution of maternally derived yolk testosterone and early developmental traits in passerine birds. Biol Lett 2005, 1:461-464

66. Schwabl H, Palacios MG, Martin TE: Selection for rapid embryo development correlates with embryo exposure to maternal androgens among passerine birds. Am Nat 2007, 170:196-206.

67. Gil D, Biard C, Lacroix A, Spottiswoode CN, Saino N, Puerta M, Moller AP: Evolution of yolk androgens in birds: development, coloniality, and sexual dichromatism. Am Nat 2007, 169:802-819.

68. Benson D, Karsch-Mizrachi I, Lipman D, Ostell J, Sayers E: GenBank. Nucleic Acids Res 2009, 37:D26-31.

69. Stajich J, Block D, Boulez K, Brenner S, Chervitz S, Dagdigian C, Fuellen G, Gilbert J, Korf I, Lapp H, et al:: The Bioperl toolkit: perl modules for the life sciences. Genome Res 2002, 12:1611-1618.

70. Edgar R: MUSCLE: multiple sequence alignment with high accuracy and high throughput. Nucleic Acids Res 2004, 32:1792-1797.

71. Pagel $M$, Meade A: A phylogenetic mixture model for detecting patternheterogeneity in gene sequence or character-state data. Syst Biol 2004, 53:571-581.

72. Tavaré S: Some probabilistic and statistical problems in the analysis of DNA sequences. American Mathematical Society: Lectures on Mathematics in the Life Sciences 1986, 17:57-86.

73. Poole AF, Stettenheim P, Gill FB: The Birds of North America: Life Histories for the 21st century Washington, D.C.: The Academy of Natural Sciences; 1992.

74. Deeming DC, Birchard GF, Crafer R, Eady PE: Egg mass and incubation period allometry in birds and reptiles: effects of phylogeny. J Zool 2006, 270:209-218.

doi: 10.1186/1471-2148-10-179

Cite this article as: Hipfner et al., Evolution of embryonic developmental period in the marine bird families Alcidae and Spheniscidae: roles for nutrition and predation? BMC Evolutionary Biology 2010, 10:179 